\title{
GESTÃO DO PROJETO POLÍTICO PEDAGÓGICO E OS SENTIDOS DA PRÁXIS DE FORMAÇÃO NA ESCOLA
}

Patrícia Rosas Porto ${ }^{1}$

\section{RESUMO}

O presente artigo de revisão surgiu da necessidade de conhecer, sistematizar e analisar a produção acadêmica objetivando realizar uma imersão na práxis de formação, relacionada a gestão do Projeto Político Pedagógico e a busca dos sentidos do fazer educativo, versando sobre os desafios impostos aos gestores escolares na realização de mudanças, na melhoria da organização da escola por meio da elaboração e gestão de um projeto que aponte os compromissos que serão assumidos por todos os integrantes da comunidade escolar e o papel da práxis de formação nesse contexto. Na relação do PPP com a práxis de formação, pesquisas apontam que o processo de construção, deveria haver mais estudo, debate, discussões sobre os problemas, para busca coletiva de soluções, e oportunidade de trocas de experiências.

Palavras-chave: Gestão Escolar, Gestão do Projeto Político Pedagógico e Práxis de formação.

\section{RESUMEN}

El presente artículo de revisión surgió de la necesidad de conocer, sistematizar y analizar la producción académica con el objetivo de realizar una inmersión en la praxis de formación, relacionada con la gestión del Proyecto Político Pedagógico y la búsqueda de los sentidos del hacer educativo, versando sobre los desafíos impuestos a los desafíos gestores escolares en la realización de cambios, en la mejora de la organización de la escuela a través de la elaboración y gestión de un proyecto que apunte los compromisos que serán asumidos por todos los integrantes de la comunidad escolar y el papel de la praxis de formación en ese contexto. En la relación del PPP con la praxis de formación, investigaciones apuntan que el proceso de construcción, debería haber más estudio, debate, discusiones sobre los problemas, para la búsqueda colectiva de soluciones, y oportunidad de intercambios de experiencias.

Palabras clave: Gestión Escolar, Gestión del Proyecto Político Pedagógico y Práxis de formación.

\footnotetext{
${ }^{1}$ Mestranda em Educação pela Universidade Estadual da Bahia (UNEB). Especialista em Planejamento e Gestão. Graduada em Pedagogia pela Universidade Católica do Salvador. Coordenadora Pedagógica, Professora da Educação Básica Pública e Vice-Gestora. E-mail: pat.rosas@yahoo.com.br
} 


\title{
RESUMO
}

O presente artigo busca discutir a trajetória histórica das Escolas Famílias Agrícolas (EFAs), desde sua origem na década de 30. Estes Centros de Formação atendem especialmente a filhos de agricultores familiares, através da Pedagogia da Alternância e vêm cada vez mais sendo reconhecidos no cenário educacional da Educação do Campo. Implantadas desde 1969 no Brasil, as EFAs têm logrado a oportunidade de acesso à educação a adolescentes e jovens camponeses, contribuindo para o desenvolvimento social das comunidades. Utilizamos dados de pesquisa realizada entre 2013-2015, durante o curso de Mestrado em Educação do Campo, realizado na UFRB. A discussão evidencia uma construção histórica a partir de experiências concretas junto a agricultores familiares na França, Itália e Brasil, com destaque para o protagonismo da participação das famílias. Entretanto, há desafios fundantes para a continuidade das EFAs, principalmente pela ausência de financiamento seguro dessas escolas.

Palavras-chaves: Escola Família Agrícola - Pedagogia da Alternância - Educação do Campo.

\begin{abstract}
This article intends to discuss the historical trajectory of the Agricultural Family Schools (EFAs), since its origins in the 1930s. Those training centers are attended by farmers's children. Those centers use the Alternanation Pedagogy and they are increasingly being recognized in the education scenario. They were implemented in Brazil since 1969, the EFAs have given the adolescents and young peasants the opportunity of education, contributing to the social development of those communities. We used data from a mastering research held between 2013 and 2015 at UFRB. The discussion shows a historical construction based on concrete experiences with farmer famillies in France, Italy and in Brazil, with emphasis on the participation of families. However, there are great challenges to the continuity of EFAs, namely the lack of funding to maintain those schools.
\end{abstract}

Keywords: Agricultural Family School - Alternation Pedagogy - Field Education.

\section{Resumen}

El presente artículo busca discutir la trayectoria histórica de las Escuelas Familias Agrícolas (EFAs), desde su origen en la década de 30. Estos Centros de Formación atienden especialmente a hijos de agricultores familiares, a través de la Pedagogía de la Alternancia y vienen cada vez más siendo reconocidos en el escenario educativa de la Educación del Campo. Implantadas desde 1969 en Brasil, las EFA han logrado la oportunidad de acceder a la educación a adolescentes y jóvenes campesinos, contribuyendo al desarrollo social de las comunidades. Utilizamos datos de investigación realizada entre 2013-2015, durante el curso de Maestría en Educación del Campo, realizado en la UFRB. La discusión evidencia una construcción histórica a partir de experiencias concretas junto a agricultores familiares en Francia, Italia y Brasil, con destaque para el protagonismo de la participación de las familias. Sin embargo, hay desafíos importantes para la continuidad de las EFA, principalmente por la ausencia de financiamiento seguro de esas escuelas.

Palabras claves: Escuela Familia Agrícola - Pedagogía de la Alternancia - Educación del Campo. 


\section{INTRODUÇÃO}

O presente artigo surge a partir de reflexões realizadas durante a constituição da pesquisa de mestrado em educação que está em andamento, quando realizava o levantamento das produções acadêmicas sobre o Projeto Político Pedagógico. Detectamos que a formação na escola se constituíram em uma das abordagens de pesquisa. Com o objetivo de tecer considerações sobre a relação entre a gestão do projeto político pedagógico e a práxis de formação na escola iniciamos essa escrita. Serão usados como referenciais teóricos livros publicados sobre o PPP e análise das produções acadêmico-científica sobre o Projeto Político Pedagógico e a práxis de formação, discutindo os dados sobre a implementação da política pública de gestão que institui o Projeto Político Pedagógico, a fim de apreender em que medida a práxis de formação acontece na escola.

Para alcançar os objetivos da pesquisa, destacamos o diálogo com os autores, para apontar como essa temática tem sido tratada, qual a concepção, quais as condições efetivas do processo de formação, quais as dificuldades e contradições do processo, bem como as discussões sobre os seus limites. A pesquisa será realizada a partir da análise de dissertações de mestrado e teses de doutorado produzidas e divulgada nos banco de dados e nos repositórios de Universidade que possuem consultas pela internet.

\section{REFERENCIAL TEÓRICO}

Sem sombra de dúvidas, o Projeto Político Pedagógico existe para garantir o direito de aprendizagem dos estudantes e assim desenvolver suas capacidades de autoconhecimento e autocuidado, o pensamento crítico, a criatividade, o espírito inovador, a abertura às diferenças, a apreciação da diversidade, a sociabilidade, a responsabilidade e a determinação. No entanto, ele também é um instrumento importante para dar sentido ao trabalho dos educadores, aqui se incluem todos os profissionais que trabalham na escola.

A educação é impulsionadora da sociedade contemporânea, se fazendo necessário repensá-la de forma radical, para além ou para mais fundo dos modelos e teorias por que optamos no passado. "Torna-se imperioso repensar a educação nos paradigmas, entendidos estes como pressupostos das estruturas mais gerais e radicais do pensamento e da ação educativa" (Marques, 2000). 
Partindo do pressuposto de que a imersão no sentido da práxis de formação pode contribuir na construção de um mundo melhor, mais humano, mais igualitário e com mais alteridade, em que o educando deve ser conduzido à prática da criticidade e seu pensamento deve ser impulsionado ao exercício da ação do pensar, se pensar e pensar no outro, na cultura a qual está inserido. Deste modo a práxis de formação não pode perder o sonho de fazer a transformação para uma vida mais satisfatória e ética. Quem administra o processo ensino-aprendizagem deve conduzir o modo de fazer, impulsionando o desenvolvimento das potencialidades.

O Projeto Político Pedagógico é o instrumento balizador para o fazer educacional e, por consequência, expressa a prática pedagógica da escola, dando direção à gestão e às atividades educacionais, pela explicitação de seu marco referencial, da educação que se deseja promover, do tipo de cidadão que se pretende formar. Constitui-se em um instrumento teórico-metodológico que organiza a ação educacional do cotidiano escolar, de uma forma refletida, sistematizada e orgânica (Vasconcellos, 1995).

O PPP é um projeto elaborado de forma participativa e colaborativa, originado no seio da coletividade docente, funcionários, alunos e pais, que dá uma identidade à instituição educacional. Conforme Veiga afirma (2001, p. 187), "é a configuração da singularidade e da particularidade da instituição educativa".

A ação do gestor está diretamente atrelada a sua concepção sobre a educação, sobre a gestão escolar e o seu papel profissional na liderança e organização da escola (Luck, 2009). No entanto, essa concepção, por mais consistente, coerente e ampla que seja, de pouco valerá, caso não seja colocada em prática mediante uma ação sistemática, de sentido global, organizada, seguramente direcionada e adequadamente especificada em seus aspectos operacionais. E essas condições somente são garantidas mediante a adoção sistemática de planejamento das ações educacionais em todos os segmentos de trabalho de escola.

\section{DIMENSÕES DO PROJETO POLÍTICO PEDAGógICO E A DIMENSÃo DA PRÁXIS DE FORMAÇÃO}

Compreender o caráter político e pedagógico do PPP nos leva a considerar três aspectos: o primeiro, é a função social de educação e de escola em uma sociedade cada vez mais excludente, compreendendo que a educação, como campo de mediações sociais, define-se sempre por seu caráter intencional e político, (Giroux,2003). Pode assim, contraditoriamente, tanto reforçar, manter, reproduzir formas de dominação e de exclusão, 
como constitui-se em espaço emancipatório, de construção de um novo projeto social, que atenda as necessidades da grande maioria da população. O segundo, é a necessária organicidade entre o PPP e os anseios da comunidade escolar, implicando a efetiva participação de todos em todos os seus momentos (elaboração, implementação, acompanhamento, avaliação). Nessa perspectiva, o projeto se expressa como uma totalidade (presente-futuro), englobando todas as dimensões da vida escolar; não se reduzindo a uma somatória de planos ou de sugestões, nem a transposição ou cópia de projetos elaborados em outras realidades escolares, não é um documento "esquecido em gavetas".

É esse o compromisso do PPP com os interesses da escola que materializa seu caráter político e pedagógico, posto que essas duas dimensões são indissociáveis. Assim, é na ação pedagógica da escola que se torna possível a efetivação de práticas sociais emancipatórias, da formação de um sujeito social, crítico, solidário, compromissado, criativo, participativo. É nessa ação que se cumpre, se realiza, a intencionalidade orientadora do projeto construído.

Compreender essa dialética entre o político e o pedagógico torna-se imprescindível para que o PPP não se torne um documento pleno de intenções e vazio de ações, de pouco adianta declarar que a finalidade da escola é "formar um sujeito critico, criativo, participativo", ou anunciar sua vinculação às teorias críticas se, nas suas práticas pedagógicas cotidianas, perduram estruturas de poder autoritárias, currículos engessados, experiências culturais empobrecidas. Ao contrário, é desvelando essas condições, afirmando seu caráter político, que a escola, por meio de seu Projeto Político Pedagógico, pode se mobilizar forças para mudanças qualitativas.

Para embasar e avolumar as discussões sobre as relações do PPP com a práxis de formação, foram concatenadas 04 pesquisas acadêmicas que versam sobre a temática relacionadas a seguir:

1 - Na tese intitulada: "Modelo de (des)(re)construção do Projeto Político Pedagógico através da Gestão Participativa“ (Lima, 2005) objetivou analisar o processo de construção do projeto político-pedagógico nas escolas municipais da região do Alto Vale do Itajaí, identificando os possíveis entraves que dificultam a elaboração, consolidação e execução desse documento. Em seguida foram realizadas as análises e implementação um novo modelo de gerenciamento através das lideranças escolares comprometidas com a construção de um projeto de gestão democrática da escola pública, através da escola de gestores, superando a prerrogativa legal, vindo a ser o documento norteador de uma ação pedagógica definida por concepções filosóficas e metodológicas. 
2 - Na dissertação de mestrado intitulada: “O diretor de escola, o Projeto Político Pedagógica e a formação dos professores em uma escola Municipal de Ensino Fundamental do interior Paulista" (Tessarin, 2007) versa sobre o diretor de escola como articulador de conhecimento, utilizando como um dos instrumentos o projeto político pedagógico para a formação dos seus professores no cotidiano escolar. O trabalho teve como objetivo proporcionar uma reflexão do papel do diretor, como ele pode organizar o espaço escolar e os tempos destinados à formação, discussões e troca de experiências, a exemplo dos conselhos de classe e série, para gestão de conhecimento e formação docente. Como resultado, o professor foi posicionado como objeto e sujeito da sua formação, tendo como destaque três competências: o saber relacionar e saber relacionar-se, o saber organizar e saber organizar-se e o saber analisar e analisar-se, tendo o diretor de escola efetivamente de papel fundamental neste processo.

3- Já na dissertação de mestrado nomeada: "Projeto Político Pedagógico: Espaço de (re)construção profissional docente em uma Perspectiva humanizadora", (Robaert, 2015) aborda a centralidade do Projeto Político-Pedagógico como grande articulador da cotidianidade escolar, como instrumento da inovação na escola e como um potencial articulador da formação permanente dos professores, através de processos auto(trans)formativos, com o desenvolvimento da instituição educativa. Essa pesquisa, buscou verificar como o PPP das escolas articula a sua cotidianidade e a formação permanente dos professores, tendo por base que essa articulação torna possível o desenvolvimento da profissionalidade docente, através da participação direta dos professores nas discussões acerca das problemáticas da escola e, por consequência, promove o desenvolvimento da instituição educativa. Constatou-se, com a pesquisa, que o PPP não é o articulador dos processos auto(trans)formativos docentes com a cotidianidade da escola e que as políticas públicas para a formação permanente de professores na Rede Municipal de Educação pesquisada têm sido implementadas dentro de uma perspectiva que vê o professor como um executor dessas políticas e não como um autor, perdendo-se um espaço privilegiado de desenvolvimento profissional docente ligado ao desenvolvimento da instituição educativa.

4- Na tese de doutorado intitulada: "Escola Pública, Currículo e Educação Emancipatória: o projeto político pedagógico como mediação", (Dalbério,2007) o objetivo geral da investigação consistiu em conhecer o que foi/é realizado no cotidiano das escolas do Município de Uberaba-MG, com relação ao Projeto Político -Pedagógico e sua interferência na formação dos professores, na gestão democrática, na participação ativa da 
comunidade escolar na tomada de decisões e, por último, na conquista da melhoria da qualidade de ensino. Constatou-se pequeno avanço no processo democrático das escolas municipais de Uberaba, entretanto, a participação é ainda muito tímida e incipiente. A comunidade pouco interfere na vida da escola, pois permanece imobilizada, sem consciência democrática e inerte mediante o descaso político quanto à qualidade da educação, que é um direito legal e legítimo. A construção e a experiência do PPP pouco interferiram também na formação dos professores, na melhoria da qualidade de ensino e, portanto, no redimensionamento do Currículo e no alcance de uma escola mais inclusiva.

A prática pedagógica existente nos processos que envolvem o PPP, particularmente a práxis de formação se constitui por meio de ações coletivas, as quais criam possibilidade para a transformação das relações educacionais, do contexto escolar e da constituição dos sujeitos que a integram. A práxis de formação da escola, precisa ser melhor desvelada, ser teorizada como uma dimensão dos processos que englobam a materialização do PPP nos moldes legalmente delineados. Abordar questões discursivas e institucionais específicas em que aprendemos e agimos, elucidar questões relacionadas à possibilidade transformadora da pedagogia do processo que envolve o PPP e a importância de se levantar questões.

A ênfase em conceituar, e descrever o PPP como uma etapa importante da organização da escola, acabou por invisibilizar e/ou descreditar o caráter transformado da práxis de formação da escola como um todo, causando uma redução na importância do processo, focando-se em questões práticas e técnicas, menosprezando a força potencializadora de formação da comunidade escolar. A pedagogia existente no processo precisa ser valorizada como resultado de disputas específicas entre os grupos para nomear a história e a experiência, o conhecimento, e o significado da vida cotidiana em seus termos. Cabe questionar a visão simplificada da dimensão pedagógica existentes nos processos que envolvem o PPP e ao papel que a pedagogia do processo desempenha em educar a comunidade escolar a respeito daquilo que a educação pública deveria realizar em uma democracia, bem como o porque de grande parte das instituições escolares fracassam nas suas experiências com o PPP.

Priva-se do caráter produtivo da pedagogia do processo e das condições institucionais que impedem a capacidade da escola de desenvolver um entendimento maior dessa pedagogia, como uma luta pela formação de identidades e de intervenção política, que não se pode escapar ao seu papel de criar espaços que possam empoderar ou desempoderar os estudantes e as práticas pedagógicas educacionais. Pensar no PPP concebido, percebido e 
vivido com um processo desencadeador das noções de protagonismo, inovação, compromisso e educação.

Assim a necessidade de criar condições para que ocorram transformações na constituição dos sujeitos por meio da apropriação do conhecimento mediado na escola, com base nos processos que envolvem o PPP, determinando também o motivo que suscitam mudanças produtivas nas ações da atividade de ensino e aprendizagem. Este movimento tem como finalidade de criar condições para que os gestores escolares, na gestão do PPP, conduzam a formação dos sujeitos individuais, apropriando-se da produção cultural e educativa elaborada durante o processo do PPP, e de humanização, uma vez que, o contexto escolar é a dimensão particular que articula ações entre a dimensão singular, própria dos sujeitos individuais e a dimensão universal, como potencial do gênero humano.

\section{PROCEDIMENTOS METODOLÓGICOS}

Utilizamos a pesquisa bibliográfica em publicações e textos científicos que versam sobre Projeto Político Pedagógico e a práxis de formação, objetivando reunir dados que sirvam de base para análise, visando propor discussões e conclusões. O trabalho é desenvolvido a partir de material elaborado a exemplo de dissertações de mestrado e teses de doutorado. Nesta perspectiva, foram utilizados nas seguintes etapas:

\section{$1^{\text {a }}$ Etapa - Fontes}

Inicialmente descreveremos as fontes que proporcionaram respostas adequadas ao panorama proposto:

a) Foram utilizados livros que discutem temáticas sobre, políticas públicas de gestão em educação, projeto político pedagógico.

b) Documentos Nacionais oficiais que instituíram a base legal para a política que institui o Projeto Político Pedagógico, parte do objeto dessa pesquisa.

Para a seleção das fontes, foram consideradas como critério de inclusão as bibliografias que abordam o arcabouço teórico que respalda a temática pesquisada.

\section{$2^{\text {a }}$ Etapa - Coleta de Dados}

A coleta de dados seguiu a seguinte premissa:

a) Leitura Exploratória de todo o material selecionado (leitura rápida que objetiva verificar se a obra consultada é de interesse para o trabalho); 
b) Leitura Seletiva (leitura mais aprofundada das partes que realmente interessam);

c) Registro das informações extraídas das fontes.

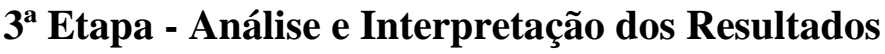

Nesta Etapa foi realizada uma leitura analítica com a finalidade de ordenar e sumariar as informações contidas nas fontes, de forma que estas possibilitassem a obtenção de respostas ao problema da pesquisa.

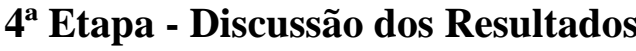

As categorias que emergiram da etapa anterior foram analisadas e discutidas a partir do referencial teórico relativo à temática do estudo.

\section{DISCUSSÕES E RESULTADOS}

A atividade gestora é aquela incumbida de orientar, harmonizar e coordenar o trabalho de um grupo, por intermédio de métodos, de acordo com o sistema ou contexto em que se insere (Luck, 2009). O significado de gestionar já traz em si certa complexidade que difere em muito de outras funções, pela diversidade de relações que envolvem. Isso sem considerar essa atividade, que é exercida no espaço escolar, no qual os grupos se caracterizam pela diversidade, os tempos entrecortados pelas rotinas de aulas, as interações são múltiplas. O tempo dessas interações é exíguo e que essa complexidade assume vários níveis muito mais elevados e precisam ser considerados quando se discute a atividade gestora.

A gestão escolar tem como foco de atuação: a mobilização, a organização e a articulação das condições materiais e humanas para garantir o avanço dos processos sócio educacionais, priorizando o conhecimento e as relações internas e externas da escola, buscando um ambiente de conhecimento, de curiosidade em relação ao mundo, para que os professores possam perceber o conhecimento que circula na sociedade e o coloquem dentro da escola, interagindo com a sociedade, exercendo o papel da escola na formação holística do aluno. Um importante elemento a ser considerado são as novas demandas que a sociedade atual traz para o gestor. O gestor escolar deve estabelecer uma relação dialógica com o Sistema Municipal e sua equipe, e a família deve ser vista como o maior interessado no sucesso dos alunos. 
Planejar constitui-se em um processo imprescindível em todos os setores da atividade educacional. É uma decorrência das condições associadas à complexidade da educação e da necessidade de sua organização, assim como das intenções de promover mudança de condições existentes e de produção de novas situações, de forma consistente (Luck, 2009). O planejamento educacional surgiu como necessidade e método da administração para o enfrentamento organizado dos desafios que demandam a intervenção humana.

Planejar a educação e a sua gestão implica em delinear e tornar clara e entendida em seus desdobramentos, a sua intenção, os seus rumos, os seus objetivos, a sua abrangência e as perspectivas de sua atuação, além de organizar, de forma articulada, todos os aspectos necessários para a sua efetivação. Para tanto, o planejamento envolve, antes de tudo, uma visão global e abrangente sobre a natureza da Educação, da gestão escolar e suas possibilidades de ação.

O conhecimento construído na troca e na participação constitui-se um grande valor estratégico para o desenvolvimento da sociedade e condição importante na qualidade da vida das pessoas. Um gestor comprometido, parceiro da construção das políticas, poderá ajudar a escola a cumprir sua vocação e sua função social. O Projeto Político Pedagógico tem como foco os estudantes, a sua formação e aprendizagem e a organização do processo pedagógico para promover essa formação e aprendizagem. Em vista disso, ele engloba o planejamento curricular, isto é, o conjunto das experiências a serem promovidas pela escola para promover a formação e aprendizagem dos estudantes.

Importante também que se consolidar a participação da comunidade como cogestora, através dos conselhos escolares e da comunidade escolar na construção do projeto político pedagógico, na gestão financeira dos recursos da escola, e na definição das relações da escola com seus estudantes, e com a própria comunidade.

Um projeto pedagógico para um mundo em constante transformação pressupõe o fortalecimento interior das instituições através principalmente da formação continuada dos profissionais da educação para que se estabeleça um tipo de saber que une o mundo interno com o externo. Isso é importante para que o professor e o educando possam preparar-se a aceitar as mudanças, sendo críticos e agentes de transformação social e assim fortalecendo a vontade de buscar alternativas para a criação e a concretização de um projeto que vai além das gavetas escolares. 


\section{CONSIDERAÇÕES FINAIS}

Abordamos a temática do Projeto Político-Pedagógico dando ênfase nos seus preceitos legais, seus conceitos, e seu propósito formador e transformador das formas de se estruturar os princípios históricos e filosóficos, dificuldades de efetivação, importância e finalidade, como também as contradições e os limites que o circundam.

A finalidade da escola é assegurar a educação do homem por meio do processo formativo, e toda aprendizagem escolar deve tender a uma educação global do homem. Com o projeto de escola, pretende-se dar coerência às políticas localmente implantadas, suscitar o dinamismo da equipe pedagógicas com problemas de consenso, para combater o fracasso escolar e inserir as crianças e jovens em seus papéis de futuros adultos.

Na relação do PPP com a práxis de formação, pesquisas apontam que para o processo de construção, deveria haver mais estudo, debate, discussões sobre os problemas, busca coletiva de soluções, como um veículo de divulgação de informações, e oportunidade de trocas de experiências, entretanto, esta ação ainda permanece desvinculada da prática. Tem se perdido oportunidade da "formação em serviço", da reflexão sobre a prática, mediante a discussão dos problemas reais da escola, de quais são as suas necessidades, da importante troca de experiências entre os pares e a busca coletiva de soluções para os problemas comuns.

O projeto político-pedagógico deve ser a ponte que liga a ação que se faz e a ação que se pretende fazer, sempre fundamentado no saber teórico, discutido, estudado e apreendido pelos sujeitos do processo educacional. Porém, essa ação não pode ser qualquer uma, para não se definir qualquer finalidade e deve-se saber que em qualquer situação, especialmente na situação educacional, não se parte de uma realidade qualquer.

O projeto Político Pedagógico é um desafio ideológico que ao invés de significar um estado futuro, ele simboliza em sua verbalização, um lugar a defender. Para (Hetkowiski, 2004) se a praxis é a esfera do ser humano e se ela revela o segredo do homem enquanto ser autocriativo, significa que imprime aos sujeitos, a partir da superação dicotômica entre teoria e prática, ou da priorização de uma sobre a outra, possibilidades de (re)criar e (re)construir a realidade humano-social, capaz de gerar novos significados à existência humana.

Para ser operatório, o projeto político pedagógico deve estabelecer indicadores de sua práxis de formação: não somente indicadores terminais referentes a objetivos fixados previamente, mas também indicadores de caminho ligados ao próprio processo do projeto, 
através das perdas e dos revezes sofridos durante a peregrinação em relação aos ganhos obtidos.

Compete a gestão do projeto político pedagógico refletir, incluir, ressignificar de que maneira a práxis de formação estrutura a experiência da comunidade escola e a vida cotidiana, bem como a relação entre as estratégias pedagógicas de negociação e de tradução.

\section{Referências}

DALBERIO, Maria Célia Borges. Escola Pública e Currículo Emancipadora: o projeto político-pedagógico como mediação. - São Paulo: PUC, 2007.

FREIRE, PAULO. Pedagogia da Autonomia: Ed. Paz e Terra, 2001

GIROUX, Henry A. Atos Impuros: A prática política dos estudos culturais - Porto Alegre : Artmed, 2003.

HETKOWSKI, TÂNIA. Políticas Públicas: Tecnologias da Informação e Comunicação e Novas Práticas Pedagógicas, Faced, Salvador, 2004.

HERNÁNDEZ SAMPIERI, Roberto. Metodologia de pesquisa. 5.ed. - Porto Alegre: Penso, 2013.

LIMA, Patrícia Rosa Traple. Modelo de (des)(re) construção do Projeto político Pedagógico através da Gestão Participativa - Florianópolis: UFSCar, 2005.

LÜCK, Heloisa. Dimensões da Gestão escolar e suas competências. Curitiba: Positivo, 2009.

Concepções e processos democráticos de gestão educacional. 9. Ed Petrópole, RJ : Vozes, 2013. Série: Cadernos de Gestão.

A Gestão Participativa na escola. 11. Ed.- Petrópolis, RJ : Vozes, 2013. Séries Cadernos de Gestão.

MARQUES, Mário. A educação no limiar do terceiro milênio, exigente de outro paradigma: Contexto e Educação, Ano 15, nº 59. Ed. Unijui, 2000.

MORIN, Edgar. Educação e complexidade: Os sete saberes e outros ensaios. 4- ed São Paulo: Cortex: 2007.

Os sete saberes necessários à educação do futuro - São Paulo: Cortez; Brasília, DF: Unesco, 2000.

ROBAERT, Samuel. Projeto Político Pedagógico: espaço de (re)construção profissional docente em uma perspectiva humanizadora. - Santa Maria: UFSM, 2015. 
TESSARIN, Marcia Maria de Oliveira. O diretor de escola, o projeto político-pedagógico e a formação de professores em uma escola municipal de ensino fundamental do interior paulista. - São Carlos: UFSCar, 2007.

VASCONCELLOS, C.S. Planejamento: plano de ensino-aprendizagem e projeto educativo. São Paulo: Libertat, 1995.

VEIGA, I. P. a (org). Projeto político pedagógico da escola: uma construção possível. Campinas: Papirus, 1995. 